\title{
Humanitarian crises due to natural disasters and armed conflict
}

\author{
${ }^{1} \mathrm{H}$ Campbell, ${ }^{2} \mathrm{H}$ Nair \\ ${ }^{1}$ Professor of Genetic Epidemiology and Public Health and Co-director, Centre for Population Health Sciences, University of Edinburgh, UK; \\ ${ }^{2}$ Senior Research Fellow, Centre for Population Health Sciences, University of Edinburgh, UK
}

TITLE Natural disasters, armed conflict, and public health

AUTHORS Leaning J, Guha-Sapir D

JOURNAL N Engl J Med 2013; 369: |836-42. http://dx.doi.org//0.1056/ NEJMral 109877

DECLARATION OF INTERESTS The authors have received funding from WHO (EMRO) to prepare and field test a manual on how to assess burden of disease in refugee camp settings.

\author{
Correspondence to H Campbell \\ Centre for Population Health \\ Sciences \\ School of Molecular, Genetic and \\ Population Health Sciences \\ University of Edinburgh \\ Teviot Place \\ Edinburgh EH8 9AG \\ UK
}

e-mail harry.campbell@ed.ac.uk

\section{SUMMARY}

The authors of this timely review work for the Centre for Health and Human Rights at Harvard University and the WHO Collaborating Centre for Research on the Epidemiology of Disasters at the University of Louvain. They draw attention to the massive scale of humanitarian crises due to natural disasters and armed conflict. They note that the immediate response to these crises has improved in recent decades with the development of standardised methods for rapid assessment of needs. These data have informed a needs-based approach to short term response but also the planning of subsequent bridging actions to give support in post-conflict/post-disaster settings. Systems such as the Standardized Monitoring and Assessment of Relief and Transitions (SMART) provide data that help assess the severity and need for emergency relief. These data also guide planning to improve resilience and preparedness for future events and to improve the effectiveness of responses to future crises.

The authors argue strongly for action to address the underlying causes, rather than merely tackling the aftermath of such disasters. The marked increasing trend in natural disasters is fuelled by climate change and associated higher temperatures, more extreme rainfall and more severe wind and water storms. The antecedents of armed conflict often lie in entrenched and increasing inequity, availability of weapons and an increasing struggle for natural resources.

\section{OPINION}

The UN High Commission for Refugees (UNHCR) published its Global Trends 2013 report in June 2014.

This revealed that the number of refugees (I6.7 million), asylum-seekers (I.I million) and internally displaced people (33.3 million) worldwide has exceeded 50 million for the first time since the Second World War. The response to these challenges of course transcends health and is rooted in human rights and conflict resolution: more than $50 \%$ of current refugees in December 2013 were from Afghanistan, Syria and Somalia.

Important lessons have been learned in tackling recent humanitarian crises: the disease burden from internal armed conflicts is not directly combat-related but is multifactorial and due to malnutrition, communicable diseases and breakdown of healthcare systems. After natural disasters the main short-term needs are water, food, sanitation and shelter but chronic needs can persist due to secondary problems such as food insecurity and long-term malnutrition.

Tackling the root causes of these crises requires a joint human rights and public health based response. It stands as a challenge to the UN system to lead and coordinate the global response from international agencies and national governments. Expertise in public health planning and administration is a key skill required at the core of both relief efforts and of preparedness planning. There are relatively few specialist doctors engaged in the efforts to address 
these enormous and increasing challenges; there is an urgent need for more specialists to tackle these multi-dimensional challenges as an essential part of national and international multi-disciplinary teams.

Training this cadre of experts requires more exposure to global public health within public health training schemes and also requires more resources to support the establishment of further centres of expertise in this field, for training, education, research and influence on policy. The authors of this article come from Centres that serve as exemplars of what is required.

\section{Exclusive offer for RCPE Collegiate Members $\mathbf{5 0 \%}$ discount on Fellowship subscriptions}

We are pleased to offer a significant discount in annual subscription rates for eligible Collegiate Members who are Consultants and wish to progress to Fellowship. ${ }^{*}$ Collegiate Members of four years' standing who are successful in their nomination for Fellowship will be able to obtain a $50 \%$ discount on their first year's Fellowship subscription and a $25 \%$ reduction on their second year's subscription, offering savings of up to $£ 300$.

Please access details of our reduced subscription rates, including concessionary elements for Fellows working less than halftime or on maternity leave, at: www.rcpe.ac.uk/join/ fellowshipoffer.php

\section{Fellowship confers a range of additional} benefits and opportunities:

- International peer and public recognition through the use of the 'FRCP Edin' postnominals.

- Professional support for revalidation/ recertification.

- The opportunity to participate in projects and working groups to determine the future direction of education and clinical medicine.

- The opportunity to help maintain national and international clinical standards by acting as an MRCP(UK) examiner.

- The opportunity to inform College responses to external policy consultations in your specialty.

- The opportunity to participate in the governance of the College through election to committees and to Council.

*Eligible candidates should normally have held a substantive Consultant post or equivalent for at least $\mathbf{1 1}$ months. If you hold such a post and are interested in being considered for Fellowship, the principal method is nomination by an existing Fellow. Please e-mail Avril Harries at a.harries@rcpe.ac.uk for a list of Fellows in your area. Alternatively, you may wish to discuss nomination with one of our Regional Advisers or consider self-nomination. 